\title{
Hedonic and nucleus accumbens neural responses to a natural reward are regulated by aversive conditioning
}

\author{
Mitchell F. Roitman, ${ }^{1,6,7}$ Robert A. Wheeler, ${ }^{2,6}$ Paul H.E. Tiesinga, ${ }^{3,4}$ Jamie D. Roitman, ${ }^{1}$ \\ and Regina M. Carelli ${ }^{2,5}$ \\ ${ }^{1}$ Department of Psychology, University of Illinois at Chicago, Chicago, Illinois 60607, USA; ${ }^{2}$ Department of Psychology, University \\ of North Carolina at Chapel Hill, Chapel Hill, North Carolina 27599, USA; ${ }^{3}$ Donders Institute for Brain, Cognition and Behavior, \\ Radboud University Nijmegen, Nijmegen 6525, The Netherlands; ${ }^{4}$ Physics and Astronomy Department, University of North Carolina, \\ Chapel Hill, North Carolina 27599, USA; ${ }^{5}$ Neuroscience Center, University of North Carolina at Chapel Hill, Chapel Hill, North \\ Carolina 27599, USA
}

\begin{abstract}
The nucleus accumbens (NAc) plays a role in hedonic reactivity to taste stimuli. Learning can alter the hedonic valence of a given stimulus, and it remains unclear how the NAc encodes this shift. The present study examined whether the population response of NAc neurons to a taste stimulus is plastic using a conditioned taste aversion (CTA) paradigm. Electrophysiological and electromyographic (EMG) responses to intraoral infusions of a sucrose $(0.3 \mathrm{M})$ solution were made in naïve rats (Day 1). Immediately following the session, half of the rats ( $n=6$; Paired) received an injection of lithium chloride (0.15 M; i.p.) to induce malaise and establish a CTA while the other half ( $n=6$; Unpaired) received a saline injection. Days later (Day 5), NAc recordings during infusions of sucrose were again made. Electrophysiological and EMG responses to sucrose did not differ between groups on Day 1. For both groups, the majority of sucrose responsive neurons exhibited a decrease in firing rate $(77 \%$ and $71 \%$ for Paired and Unpaired, respectively). Following conditioning, in Paired rats, EMG responses were indicative of aversion. Moreover, the majority of responsive NAc neurons now exhibited an increase in firing rate (69\%). Responses in Unpaired rats were unchanged by the experience. Thus, the NAc differentially encodes the hedonic value of the same stimulus based on learned associations.
\end{abstract}

[Supplemental material is available online at http://www.learnmem.org.]

Our search for sustenance and pleasurable stimuli is often balanced by our desire to avoid punishment and harm. Similarly, neural systems responsible for generating approach behavior must be countered by signals that suppress approach behavior under contexts where approach is dangerous or maladaptive (Hoebel et al. 2007). The nucleus accumbens (NAc) is acutely involved in food intake and goal-directed, approach behavior. Pharmacological manipulations of the NAc promote food intake even in sated rats (Maldonado-Irizarry and Kelley 1995; Stratford and Kelley 1997). Lesions or inactivation of the NAc impair conditioned approach behavior (Cardinal et al. 2002; Blaiss and Janak 2009). Interestingly, drugs that lead to inhibition of select regions of the NAc increase positive hedonic responses to palatable taste solutions (Pecina and Berridge 2005). Recordings from individual NAc neurons have mirrored these findings. We and others have shown that consumption of palatable food stimuli is associated with decreases in the firing rate of the majority of responsive NAc neurons (Nicola et al. 2004b; Roitman et al. 2005; Taha and Fields 2005; Wheeler et al. 2008). In addition, decreases in NAc neural activity are associated with bouts of licking behavior for

\footnotetext{
${ }^{6}$ These authors contributed equally to this work.

${ }^{7}$ Corresponding author.

E-mail mroitman@uic.edu; fax (312) 413-4122.

Article is online at http://www.learnmem.org/cgi/doi/10.1101//m.1869710.
}

palatable stimuli (Taha and Fields 2006), and disruption of these decreases halt feeding bouts (Krause et al. 2010). Finally, decreases in NAc neural activity are associated with preferred locations previously paired with drug reward (German and Fields 2007). Thus, decreases in NAc activity appear to be closely linked to positive hedonic stimuli, stimuli that have been explicitly paired with them and behavioral approach.

The NAc is also responsive to aversive stimuli (Carlezon and Thomas 2009; Levita et al. 2009). The delivery of aversive taste stimuli to rats is associated with increases in the firing rate of the majority of responsive NAc neurons (Roitman et al. 2005; Wheeler et al. 2008). In addition to responding to primary appetitive and aversive taste stimuli, NAc neurons develop responses to predictors of reward and aversion. Individual NAc neurons selectively encode cues that predict either appetitive (Roitman et al. 2005; Day et al. 2006) or aversive (Roitman et al. 2005) stimuli following purely Pavlovian conditioning or a combination of instrumental and Pavlovian conditioning (Setlow et al. 2003; Nicola et al. 2004a). NAc neurons come to encode departure from locations not associated with reward with the majority response being that of excitation (German and Fields 2007). Thus, NAc neurons appear to encode aversive stimuli and withdrawal behavior with increases in activity. These and other findings have led to the recent postulation that reward and aversion are differentially encoded by the activity of NAc neurons (Carlezon and Thomas 2009). 
Data supportive of the activity hypothesis (Carlezon and Thomas 2009) have been generated by the use of different stimuli to serve as appetitive or aversive primary or predictive stimuli. Thus, selective encoding could be biased by the sensory properties of each stimulus rather than their hedonic valence. When a novel, palatable taste is paired with visceral malaise, a Pavlovian association is made and a conditioned taste aversion (CTA) is established. Subsequent exposure to the once palatable stimulus is met with avoidance or aversion and rejection (Garcia et al. 1974; Schafe et al. 1995). Thus, the same taste stimulus can either be appetitive or aversive, depending on Pavlovian associations. Here, individual NAc neurons were recorded in rats (Paired) before (Day 1) and after a CTA (Day 5) was established and compared with rats that received equal exposure to the same stimuli but in an unpaired manner (Unpaired), and hence no CTA developed. Simultaneously, oro-motor behavior was characterized to provide an index of the associative strength of the taste stimulus. Using this paradigm, we determined that the population response of the NAc does indeed encode hedonic valence.

\section{Results}

\section{Electromyographic (EMG) analyses reveal the formation of a CTA}

EMG analysis of the anterior digastric muscle during taste exposure and licking behavior can differentiate hedonic taste reactivity (Travers and Norgren 1986; Kaplan et al. 1995; Grill et al. 1996). Specifically, "gapes," which are indicative of aversive taste reactivity (Grill and Norgren 1978; Berridge 2009), are characterized by less frequent contractions of the anterior digastric muscle that are of significantly longer duration (Travers and Norgren 1986). Here, the duration and number of anterior digastric muscle contractions during the 4-sec intraoral infusions of sucrose were measured across the 30 infusions on Day 1 and Day 5 recording sessions (Fig. 1). A three-way ANOVA (trial $\times$ day $\times$ group) conducted on contraction duration revealed significant main effects of day $\left(F_{(1,533)}=156.1 ; P<0.0001\right)$ and group $\left(F_{(1,533)}=157.8\right.$; $P<0.0001)$, and a significant day $\times$ group interaction $\left(F_{(1,533)}=\right.$ 127.5; $P<0.0001)$. A post-hoc Tukey's test on the significant interaction revealed that muscle contractions were significantly longer in Paired rats on Day $5(0.112 \pm 0.001 \mathrm{sec}$, mean \pm SEM $)$ than in Paired rats on Day $1(0.075 \pm 0.001 \mathrm{sec})$, and Unpaired rats on either Day $1(0.073 \pm 0.002 \mathrm{sec})$ or Day $5(0.075 \pm 0.002$ $\mathrm{sec})$. In addition, a three-way ANOVA (trial $\times$ day $\times$ group) conducted on number of contractions revealed significant main effects of day $\left(F_{(1,533)}=178.2 ; P<0.0001\right)$ and group $\left(F_{(1,533)}=\right.$ $276.2 ; P<0.0001)$, and a significant day $\times$ group interaction $\left(F_{(1,533)}=133.9 ; P<0.0001\right)$. A post-hoc Tukey's test on the significant interaction revealed that Paired rats exhibited significantly fewer contractions on Day $5(14.04 \pm 0.33$, mean \pm SEM) than Day $1(22.54 \pm 0.32$, mean \pm SEM), and Unpaired rats on either Day $1(24.27 \pm 0.36$, mean \pm SEM) or Day $5(23.66 \pm 0.35$, mean \pm SEM). Thus, on Day 5 only Paired rats showed a pattern of EMG activity-fewer contractions of longer duration-consistent with aversive taste reactivity.

\section{Recordings made in the shell and core subcompartments of the nucleus accumbens}

Histological verification of electrode placements revealed that the majority of microwires were implanted within the NAc. Figure 2 shows the recording locations of phasically active cells recorded on the implanted microwires. For Unpaired rats, a total of 90 cells were recorded on Day 1 (65 and 25 in the shell and core, respectively) and 86 cells were recorded on Day 5 (60 and 26 in the shell and core, respectively). For Paired rats, a total of 81 cells were

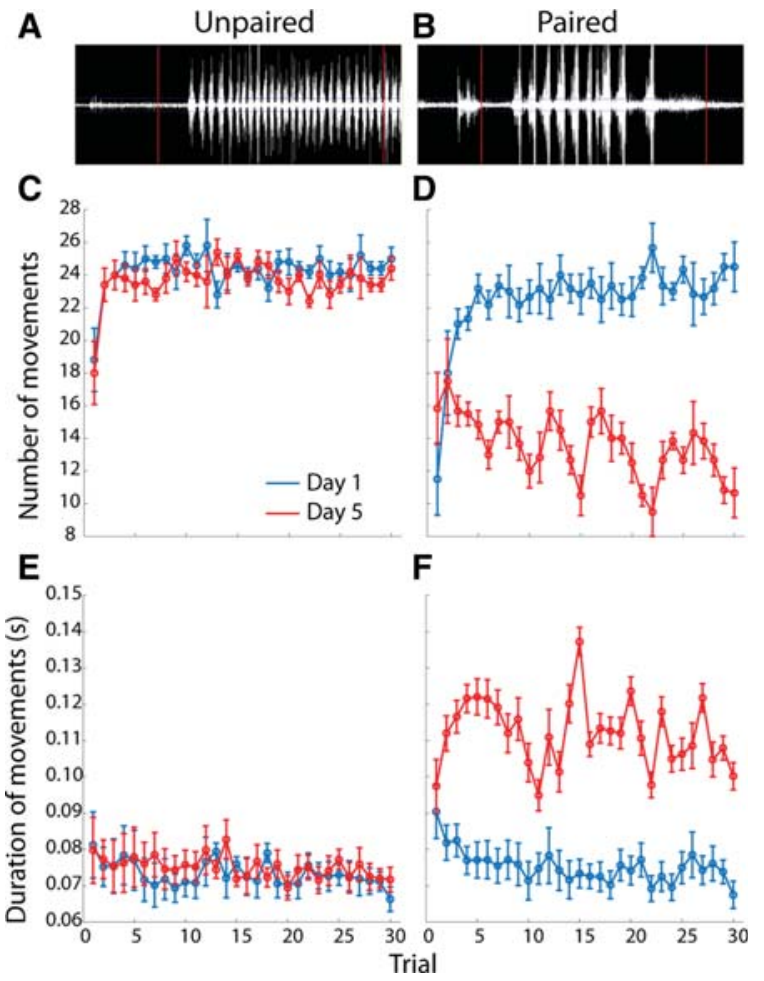

Figure 1. EMG responses of the anterior digastric muscle to intraorally infused sucrose reflect the formation of a CTA. $(A)$ Representative raw EMG trace recorded from the anterior digastric muscle in an Unpaired rat. $(B)$ Representative raw EMG trace recorded from the anterior digastric muscle in a Paired rat. In both $A$ and $B$, vertical red lines denote, from left to right, the beginning and end of the 4-sec intraoral infusion of $0.3 \mathrm{M}$ sucrose. In Unpaired rats $(n=6)$, experience with sucrose (Day 5, red) and $\mathrm{LiCl}$ injections did not alter the number $(C)$ or duration $(E)$ of EMG responses across the 30 -trial intraoral infusion session relative to the EMG responses observed in the same rats on Day 1 (blue). In Paired rats $(n=6)$, experience with sucrose (Day 5 , red) and LiCl injections led to significant decreases in the number $(D)$ and increases in the duration $(F)$ of EMG responses across the 30 -trial intraoral infusion session relative to the EMG responses observed in the same rats on Day 1 (blue).

recorded on Day 1 (56 and 25 in the shell and core, respectively) and 92 cells were recorded on Day 5 (58 and 34 in the shell and core, respectively). Recordings made in both Unpaired and Paired rats revealed phasic electrophysiological responses to intraoral infusions of sucrose. Consistent with previous electrophysiological investigations (Nicola et al. 2004b; Roitman et al. 2005; Taha and Fields 2006; Wheeler et al. 2008), we did not observe differences in the frequencies of phasic responses of any kind across NAc subcompartments (see Table 1 and Supplemental materials). Cells were classified as decreasing, increasing, or nonphasic (see Materials and Methods). Figure 3A shows an example of an increasing neuron and Figure $3 \mathrm{~B}$ shows an example of a decreasing neuron.

\section{Phasic responses in Unpaired rats}

NAc recordings were made in Unpaired rats on Day 1 and Day 5. Figure 4 (top) shows the normalized average firing rates of each phasic neuron on Day 1 (Fig. 4A) and Day 5 (Fig. 4B) for the 10 sec prior to, the $4 \mathrm{sec}$ of, and $6 \mathrm{sec}$ after the intraoral infusion of sucrose. On Day 1, 51 of 90 (57\%) neurons recorded had a phasic response to sucrose. Of these phasic cells, the clear majority (36 of $51,71 \%$ ) exhibited a decrease in firing rate during the intraoral infusion of sucrose (Fig. 4A). These proportions are consistent 


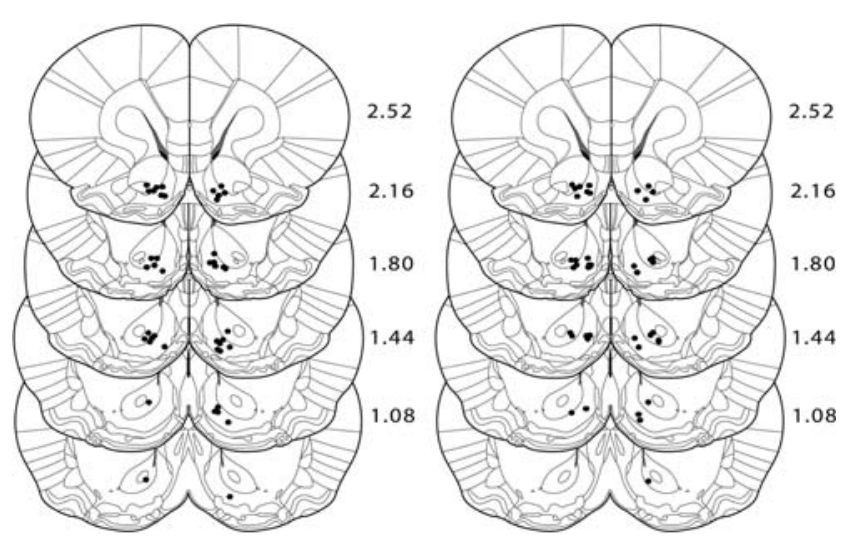

Figure 2. Histological verification of electrode placements. Lesion sites in Unpaired (left) and Paired (right) rats of confirmed electrode placements in the nucleus accumbens are shown. Placements in the NAc are based on a stereotaxic atlas (Paxinos and Watson 2007).

with previous reports (Roitman et al. 2005; Wheeler et al. 2008) and collectively support the finding that NAc neurons of naïve rats respond to the taste of sucrose predominantly with decreases in activity. In the same rats, the response to sucrose on Day 5 was comparable to that observed on Day 1 . Thirty-six of 86 (44\%) cells had a phasic response to sucrose. Of these phasic cells, the clear majority (24 of 36, 67\%) exhibited a decrease in firing rate during the intraoral infusion of sucrose (Fig. 4B). This response profile did not differ from the responses observed on Day $1,\left(\chi^{2}=0.00 ; P>\right.$ $0.05)$. Figure $4 \mathrm{C}$ and $\mathrm{D}$ shows the average population activity for each condition across all phasic neurons (green), as well as for the subpopulations of decreasing (blue) and increasing (red) neurons separately. For Unpaired rats, there was a significant main effect of time on firing rate across all phasic neurons $\left(F_{(19,1700)}=\right.$ 3.23; $P<0.001$ ) but no effect of day and no significant interactions, further suggesting that NAc responses in Unpaired rats were not affected by explicitly unpaired $\mathrm{LiCl}$ exposure.

\section{Phasic responses in Paired rats}

In contrast to Unpaired rats, NAc responses in Paired rats exhibited profound differences after conditioning. On Day 1, 35 of 81 (43\%) cells had a phasic response to sucrose. Of these phasic cells, the clear majority ( 27 of $35,77 \%$ ) exhibited a decrease in firing

Table 1. Distribution of taste-responsive neurons across NAC subregions

\begin{tabular}{|c|c|c|c|c|c|c|}
\hline \multirow[b]{2}{*}{ Region } & & & \multicolumn{4}{|c|}{ Response } \\
\hline & & & NP & INC & DEC & TOT \\
\hline \multicolumn{7}{|l|}{ Shell } \\
\hline & Unpaired & Day 1 & 25 & 10 & 30 & 65 \\
\hline & & Day 5 & 38 & 10 & 12 & 60 \\
\hline & Paired & Day 1 & 31 & 6 & 19 & 56 \\
\hline & & Day 5 & 34 & 18 & 6 & 58 \\
\hline \multicolumn{7}{|l|}{ Core } \\
\hline & Unpaired & Day 1 & 14 & 5 & 6 & 25 \\
\hline & & Day 5 & 12 & 2 & 12 & 26 \\
\hline & Paired & Day 1 & 15 & 2 & 8 & 25 \\
\hline & & Day 5 & 19 & 9 & 6 & 34 \\
\hline \multicolumn{7}{|l|}{ NAc } \\
\hline & Unpaired & Day 1 & 39 & 15 & 36 & 90 \\
\hline & & Day 5 & 50 & 12 & 24 & 86 \\
\hline & Paired & Day 1 & 46 & 8 & 27 & 81 \\
\hline & & Day 5 & 53 & 27 & 12 & 92 \\
\hline
\end{tabular}

rate during the intraoral infusion of sucrose (Fig. 5A) - a proportion similar to that observed in Unpaired rats on Day 1 . In the same rats, a similar number of neurons-39 of 92 (44\%)—exhibited a phasic response to sucrose on Day 5; however, the pattern of activity was remarkably different. Of these phasic cells, a minority (12 of 39, 31\%) exhibited a decrease in firing rate during the intraoral infusion of sucrose (Fig. 5B). Thus, the proportion of decreasing to increasing cells changed in the Paired rats following conditioning as evidenced by the significantly greater proportion of increasing neurons $\left(69 \% ; \chi^{2}=47.75 ; P<0.001\right)$. Figure $5 \mathrm{C}$ and $D$ shows the average neural response across all phasic cells (green), as well as decreasing (blue) and increasing (red) separately. For Paired rats, the overall average level of activity (green) significantly varied as a function of time $\left(F_{(19,1440)}=2.27 ; P<0.001\right)$, and Day $\left(F_{(1,1440)}=93.89 ; P<0.001\right)$. Critically, there was a significant interaction $\left(F_{(19,1440)}=7.61 ; P<0.001\right)$ supporting the finding that in Paired rats, the population response to sucrose changed as a function of conditioning. In addition, phasic responses in Paired rats lasted significantly longer on Day 5 relative to Day 1 and Unpaired rats on either Day (see Supplemental material, Supplemental Figs. S1,S2).

\section{Population responses}

The differences observed in the population response of NAc neurons on Day 5 in the Paired group could be due to a change in the relative proportions of increasing and decreasing neurons or a change in the magnitude of phasic responses in increasing or decreasing cells. To investigate this possibility, the average normalized firing rate during the infusion (denoted by gray boxes in Figs. 4C,D; 5C,D) was separately compared for decreasing and increasing cells across days (Day 1 vs. Day 5; Fig. 6A). For increasing neurons (solid outline), we did not observe any significant differences in response magnitude across day (Day 1 vs. Day 5) $\left(F_{(1,244)}=2.87 ; \quad P>0.05\right)$ or group (Unpaired vs. Paired) $\left(F_{(1,244)}=3.45 ; P>0.05\right)$. There were also no significant effects of day $\left(F_{(1,392)}=3.01 ; P>0.05\right)$ or group $\left(F_{(1,392)}=0.60 ; P>\right.$ $0.05)$ on decreasing cells (dashed outline). When averaged across all phasic neurons, though, we found a significant interaction between day and group (Fig. $6 \mathrm{~B}, F_{(1,640)}=29.37 ; P<0.0001$ ). A post-hoc Tukey's test on the significant interaction revealed that normalized firing rate was significantly different in the Paired rats on Day 5 relative to all others (all $P<0.0001$ ), but that the remaining three conditions did not differ (all $P>0.05$ ).

\section{Discussion}

The NAc has received considerable attention as part of the brain's reward circuitry. However, recent work has demonstrated that it is also responsive to aversive stimuli. Most investigations of NAc encoding of reward and aversion have either been conducted in separate studies or used different stimuli (Setlow et al. 2003; Roitman et al. 2005; Levita et al. 2009). Here we show that the NAc differentially encodes the same stimulus depending on its hedonic value. CTA was used as a means to alter the hedonic value of a sucrose solution. Two groups of naïve rats had similar EMG and NAc responses to intraoral infusions of sucrose. Following experience with the malaise-inducing agent $\mathrm{LiCl}$ (Bernstein et al. 1992) unpaired with sucrose infusions, rats showed behavioral and neural responses which were unchanged relative to naïve conditions. In sharp contrast, rats that had $\mathrm{LiCl}$ injections explicitly paired with sucrose infusions exhibited a remarkably different pattern of behavioral responses to intraoral sucrose relative to responses made prior to conditioning (Day 1), with those responses indicative of aversion. Consistent with the altered behavioral response, the population response of NAc neurons in 
A

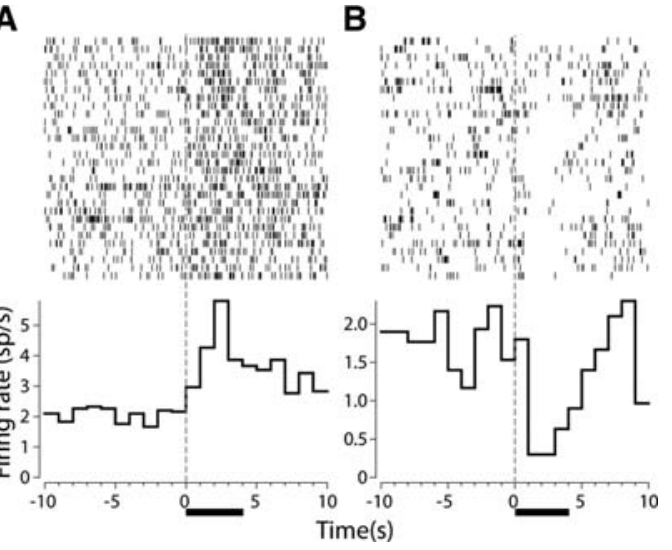

Figure 3. Raster plots (above) and perievent histograms (below) of two representative cells in the NAC that respond to intraoral infusions of sucrose. (A) An increasing neuron recorded in a Paired rat on Day 5. (B) A decreasing neuron recorded in an Unpaired rat on Day 5. For both graphs, data are aligned to the onset of the infusion $(t=0 \mathrm{sec})$ and the horizontal black bar denotes the duration of the intraoral infusion.

Paired rats was significantly changed relative to Unpaired rats. Collectively, these data demonstrate that the NAc processes aversive stimuli but in a qualitatively different manner from rewarding stimuli, and lend support to the emerging hypothesis that reward and aversion are encoded by opposite changes in NAc neural activity (Carlezon and Thomas 2009).

Inhibition of the NAc is associated with enhanced hedonic evaluation of taste stimuli. Injection of the GABA receptor agonist muscimol into subregions of the NAc increase positive hedonic responses to an intraorally delivered taste stimulus (Reynolds and Berridge 2002). In addition, intra-NAc injections of the $\mu$ opioid receptor agonist D-Ala2-N-MePhe4-Glycol5-enkephalin (DAMGO) increased positive hedonic responses to rewarding sucrose and decreased negative hedonic responses to aversive quinine (Pecina and Berridge 2005). The cannabinoid CB1 receptor ligand, anandamide also increased positive hedonic responses to sucrose (Mahler et al. 2007). Each of these pharmacological treatments has inhibitory action on the NAc (Cota et al. 2006). Thus, decreases in NAc activity appear to be correlated with increased positive affective responses to taste stimuli. We (Roitman et al. 2005; Wheeler et al. 2008) and others (Nicola et al. 2004b; Taha and Fields 2005, 2006) have shown that rewarding taste stimuli are correlated with decreases in firing rate from a majority of responsive NAc neurons. These findings were replicated here. On Day 1, the majority $(\sim 70 \%)$ of NAc neurons responsive to intraoral infusions of sucrose exhibited decreases in firing rate. This phenomenon was unchanged by experience with sucrose as a similar $P>0.05)$.
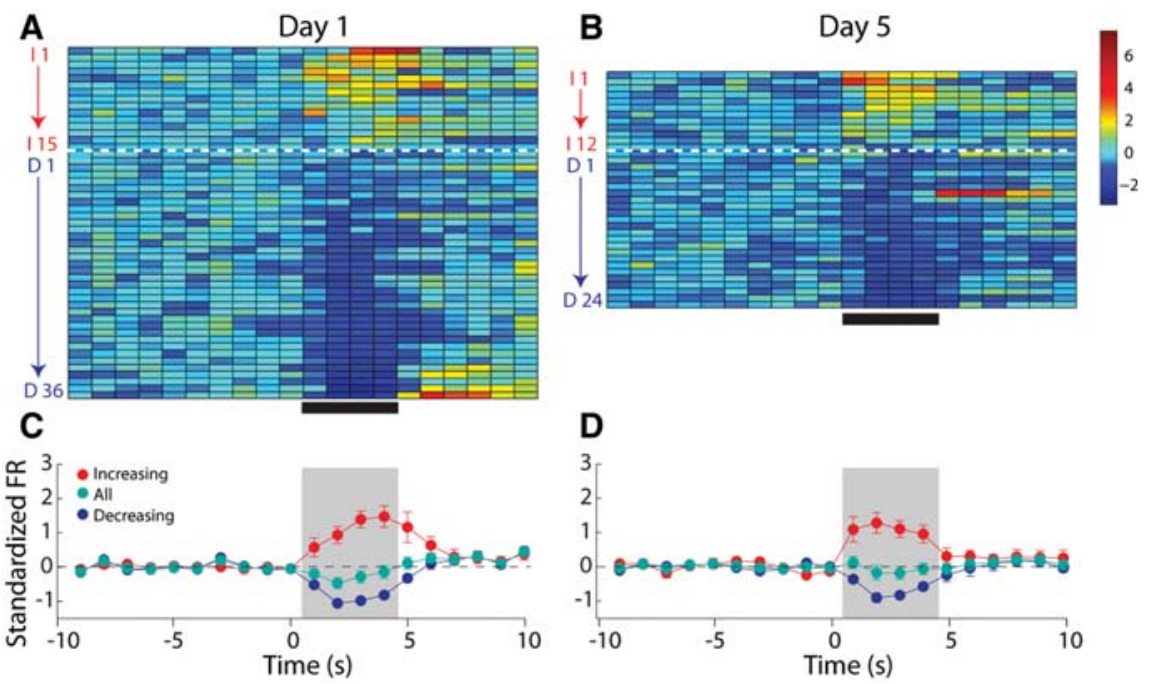

percentage of sucrose-responsive NAc neurons, recorded in Unpaired rats on Day 5, exhibited decreases in firing rate.

While there is converging evidence that inhibition of the NAc is correlated with aspects of reward, far less attention has been paid to how the NAc encodes aversive stimuli. However, there is a growing literature suggesting that increased NAc activity is correlated with aversive states. Functional magnetic imaging (fMRI) has revealed that the NAc is responsive to both rewarding and aversive events (Becerra et al. 2001; Gottfried et al. 2002; Cooper and Knutson 2008). Recently, Levita et al. (2009) used auditory stimuli that were rated as either pleasant or unpleasant. Both primary rewarding and aversive stimuli evoked increases in the blood oxygen level dependent (BOLD) signal. Interestingly, the BOLD signal was significantly larger in response to the onset of the unpleasant relative to the pleasant auditory stimulus. This result is suggestive of increased NAc activity in response to aversion relative to reward. We have previously shown that a primary aversive stimulus (e.g., quinine) evokes increases in NAc neural activity in the majority of responsive neurons (Roitman et al. 2005). A similar majority of NAc increases was correlated with a taste stimulus that acquired aversive properties after being paired with cocaine self-administration sessions (Wheeler et al. 2008). In both sets of electrophysiological studies, taste stimuli that were qualitatively different were compared. Here, we show that the same stimulus is differentially encoded by the NAc, depending on whether it is perceived as rewarding or aversive. Paired rats responded to the taste of sucrose as if it were aversive. The majority of sucrose responsive NAc neurons increased their

Figure 4. In Unpaired rats, experience does not affect the population response of NAc neurons to intraoral infusions of sucrose. (Left) Representation of all sucrose responsive NAc neurons recorded on Day 1, under naïve conditions. (A) The colorplot shows the normalized firing rate (1-sec bins) of each neuron that had a statistically significant change in firing rate in response to intraoral infusions. Each row represents the activity of one neuron. Data are aligned to the start of the intraoral infusion $(t=0 \mathrm{sec})$. Normalized firing rate is shown in color. Neurons are organized such that the strongest increasing neuron is at the top and the strongest decreasing neuron is on the bottom. Increasing neurons are highlighted by the red letter " $\mathrm{I}$ " and number. The horizontal dashed white line separates neurons that exhibited a significant increase $($ above; $n=15)$ from those that exhibited a significant decrease $(n=36)$ in firing rate in response to sucrose infusions. Decreasing neurons are highlighted by the blue letter " $\mathrm{D}$ " and number. (C) Average normalized response of decreasing (blue circles) and increasing (red circles) neurons as well as the overall population response (green circles) to sucrose infusions on Day 1. (Right) Representation of all sucrose responsive NAc neurons recorded on Day 5, after explicitly Unpaired LiCl experience. $(B)$ Increasing $(n=12)$ and decreasing $(n=24)$ neurons recorded on Day 5 are shown as in $A$. (D) Average normalized response of decreasing (blue circles) and increasing (red circles) neurons as well as the overall population response (green circles) to sucrose infusions on Day 5. The ratio of increasing to decreasing neurons was no different on Day 1 vs. Day $5\left(\chi^{2}=0.00\right.$; 
A
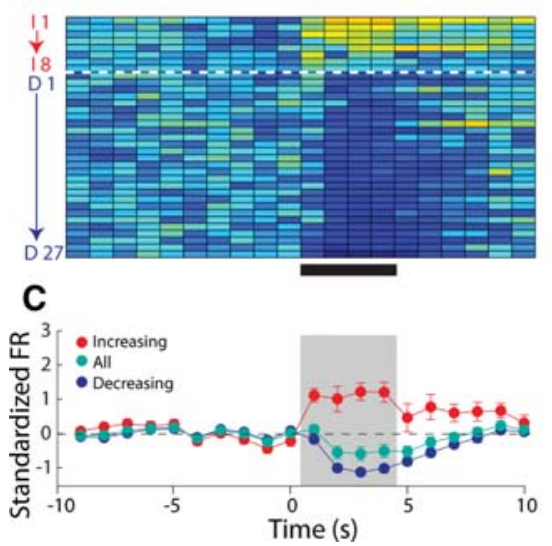

Figure 5. In Paired rats, experience alters the population response of NAc neurons to intraoral infusions of sucrose. Left: Representation of all sucrose responsive NAc neurons recorded on Day 1, under naïve conditions. (A) The colorplot shows the normalized firing rate (1-sec bins) of each neuron that had a statistically significant change in firing rate in response to intraoral infusions. Each row represents the activity of one neuron. Data are aligned to the start of the intraoral infusion $(t=0 \mathrm{sec})$. Normalized firing rate is shown in color. Neurons are organized such that the strongest increasing neuron is at the top and the strongest decreasing neuron is on the bottom. Increasing neurons are highlighted by the red letter "I" and number. The horizontal dashed white line separates neurons that exhibited a significant increase (above; $n=8$ ) from those that exhibited a significant decrease $(n=27)$ in firing rate in response to sucrose infusions. Decreasing neurons are highlighted by the blue letter " $D$ " and number. (C) Average normalized response of decreasing (blue circles) and increasing (red circles) neurons as well as the overall population response (green circles) to sucrose infusions on Day 1. Right: Representation of all sucrose responsive NAc neurons recorded on Day 5, after explicitly Paired $\mathrm{LiCl}$ experience. (B) Increasing $(n=27)$ and decreasing $(n=12)$ neurons are shown as in $A$. $(D)$ Average normalized response of decreasing (blue circles) and increasing (red circles) neurons as well as the overall population response (green circles) to sucrose infusions on Day 5. Importantly, the ratio of increasing to decreasing neurons was significantly different on Day 5 vs. Day $1\left(\chi^{2}=47.75 ; P<0.001\right)$.

activity. In addition, neural responses in paired rats persisted significantly longer on Day 5. Collectively, these data are consistent with the recent postulation that reward and aversion are encoded by differential NAc activity: rewarding stimuli are encoded by decreases and aversive stimuli are encoded by increases in NAc neural activity (Carlezon and Thomas 2009). Future work will be aimed at determining if these increases in NAc activity are correlated with behavioral inhibition or rejection responses.

While the direction of the population response of NAc neurons to the sucrose solution was dependent on its hedonic valence, it is possible that rather than just encoding hedonic valence, NAc population responses facilitated appetitive oromotor responses in Unpaired and suppressed them in Paired rats. The majority $(>90 \%)$ of NAc neurons are medium spiny GABA-ergic projection neurons (Meredith 1999). Thus, decreases in NAc neural activity may serve as a release of inhibition on important motor centers (Saper et al. 2002; Carlezon and Thomas 2009). Recent work suggests that decreases in NAc neural activity are directly correlated with behavior directed at the consumption of rewarding stimuli (Krause et al. 2010). Along these lines, the increase in NAc activity observed following the establishment of CTA may serve to inhibit circuits that ultimately lead to oro-motor behavior. Indeed, fewer movements of the anterior digastric muscle were evoked by sucrose in Paired rats. The NAc projects, in part, to the retrorubral field, which has recently been shown to be involved in anterior digastric muscle contractions (Uchida et al. 2005). Thus, there is a plausible circuit whereby NAc activity could differentially affect oro-motor behavior. Determining whether NAc neurons reflect purely hedonic responses or responses to hedonic stimuli that ultimately lead to permission or inhibition of motor output will be a rich area for future study. either LiCl-induced malaise or exposure to the malaise-predicting conditioned stimulus, could result in plastic changes within the NAc itself leading to enhanced excitability. Another intriguing possibility is a change in input strength. The amygdala, specifically the basolateral nucleus of the amygdala (BLA) projects to the NAc and can influence NAc activity (McGinty and Grace 2009). Importantly, the BLA appears to be a critical integrator of taste and visceral information for the formation of a CTA (Barot et al. 2008). Thus, plasticity within
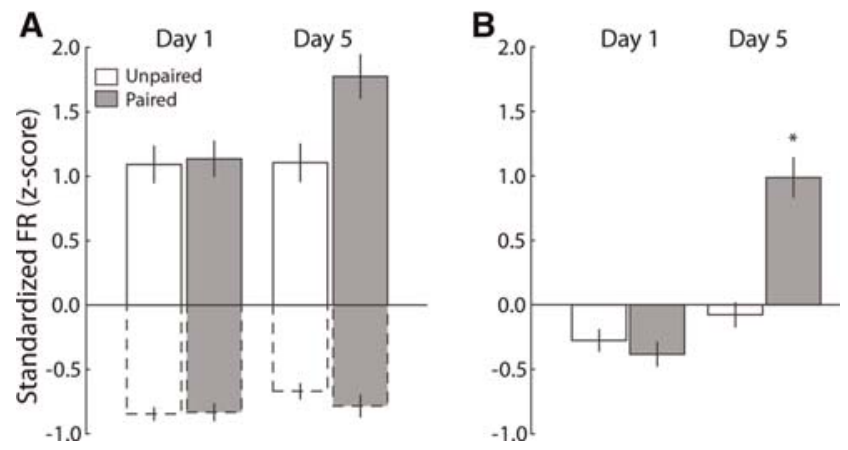

Figure 6. Although the magnitude of increased and decreased responses do not differ across days of testing, the overall response across the population reflects a hedonic shift. $(A)$ The magnitude of the response to sucrose of increasing (solid outlined bars) and decreasing (dashed outlined bars) neurons does not differ based on day (Day 1 vs. Day 5) or pairing (Unpaired vs. Paired). (B) The average firing rate for all sucrose-responsive neurons changes based on pairing. The average firing rate was significantly higher on Day 5 but only in Paired rats. Bars represent means \pm 1 SEM. $\left(^{*}\right)$ Denotes significant difference $(P<0.001)$ relative to all other bars. 
NAc-projecting BLA networks maybe responsible for the change in the NAc population response exhibited in Paired rats. Future studies will address the nature of the change in the NAc population response following CTA conditioning.

\section{Materials and Methods}

\section{Subjects and surgery}

Naïve male Sprague-Dawley rats $(n=12)$ were singly housed on a 12:12 light:dark schedule with water and food available ad libitum. All procedures were approved by the University of North Carolina, Chapel Hill Institutional Animal Care and Use Committee. To prepare rats for intraoral infusions and electrophysiological recordings, they were anesthetized with ketamine hydrochloride $(100 \mathrm{mg} / \mathrm{kg}, \mathrm{i} . \mathrm{m}$.$) and xylazine hydrochloride (20 \mathrm{mg} / \mathrm{kg}, \mathrm{i} . \mathrm{m}$.$) ,$ implanted with bilateral intraoral catheters (Roitman et al. 2005) just lateral to the first maxillary molar. Next, a small, midline incision on the ventral surface just posterior to the jaw was made and using blunt dissection the anterior digastric muscle was exposed. For EMG recordings of the anterior digastric muscle, the uninsulated tips of two, seven-strand stainless steel wires (A-M Systems) were implanted in the anterior digastric muscle. The free ends were then led subcutaneously out of an incision in the top of the head and mated to a 10-pin connector (see Kaplan et al. 1995 for details). Another stainless steel wire was wrapped around a skull screw and mated to the same connector to serve as a ground. Rats were then placed into a stereotaxic frame and holes were drilled bilaterally over the NAc. For electrophysiological recordings, eight-wire microelectrode arrays (NB Labs) were implanted bilaterally in the NAc. The coordinates used, in accordance with the atlas of Paxinos and Watson (2007), were as follows: AP, $+1.7 \mathrm{~mm}$; ML, \pm 0.8 to $\pm 1.3 \mathrm{~mm}$; and $\mathrm{DV},-6.5 \mathrm{~mm}$ from the surface. For each array, another wire was wrapped around a skull screw to serve as ground. The EMG connector, microelectrode arrays, and intraoral cannulae were affixed to the skull using skull screws and dental acrylic. Rats were permitted at least $1 \mathrm{wk}$ to recover from surgery before testing.

\section{CTA procedure}

Naïve rats were placed in a Plexiglas chamber and were connected to flexible recording cables (Plexon Inc.) attached to a commutator (Crist Instruments, Inc.), which permitted virtually unrestrained movement within the chamber. In addition, a fluid line was connected to the intraoral cannula. Fluid was gravity fed into the intraoral cannula and controlled by a solenoid valve. On a single trial, the solenoid valve opened for $4 \mathrm{sec}$, resulting in the delivery of $200 \mu \mathrm{L}$ of a $0.3-\mathrm{M}$ sucrose solution. On the first day of testing (Day 1), rats received 30 intraoral infusions spaced 1 min apart. Neural and EMG activity was continuously recorded. Immediately following the session, half the rats $(n=6)$ were injected with $0.15 \mathrm{M} \mathrm{LiCl}(20 \mathrm{~mL} / \mathrm{kg}$; i.p.; Paired) and the other half $(n=6)$ were injected with $0.15 \mathrm{M} \mathrm{NaCl}(20 \mathrm{~mL} / \mathrm{kg}$, i.p.; Unpaired). $\mathrm{LiCl}$ induces visceral malaise and, when paired with a novel taste solution, results in the formation of a CTA (Schafe et al. 1995). The following day, rats received injections of the solution they did not receive the prior day (i.e., Paired rats received $0.15 \mathrm{M} \mathrm{NaCl}$ and Unpaired received $0.15 \mathrm{M} \mathrm{LiCl}$ ), but no intraoral infusions were made. This 2-d procedure was repeated once without recording. On the fifth day (Day 5), all rats received intraoral infusions while EMG and electrophysiological recordings were simultaneously made. Thus, all rats had equal exposure to sucrose and $\mathrm{LiCl}$, but half of all rats had this experience paired with illness (Paired) while the other rats had the experience unpaired (Unpaired).

\section{Electrophysiological and EMG recordings}

Electrophysiological procedures have been described in detail previously (Carelli and Deadwyler 1994; Carelli et al. 2000). Briefly, before the start of the behavioral session, each rat was placed into a Plexiglas chamber within a sound-attenuating box. Rats were connected to a flexible recording cable (Plexon Inc.) attached to a commutator (Med Associates, Inc.), which permitted virtually unrestrained movement within the chamber. NAc activity was recorded differentially between each active wire and an inactive wire chosen for an absence of neuronal activity. Online isolation and discrimination were accomplished using a commercially available neurophysiological system (multichannel acquisition processor [MAP] system; Plexon, Inc.). First, a threshold was set such that only waveforms 4.5 standard deviations from noise were time stamped. Next, 1000 waveforms were collected on each wire and fitted in mathematical space using principal component analysis. Single neurons were then identified based on cluster analysis multiple window discrimination modules and high-speed analog-to-digital signal processing in conjunction with computer software enabled isolation of neuronal signals on the basis of waveform analysis. The neurophysiological system incorporated an array of digital signal processors (DSPs) for continuous spike recognition. The DSPs provided a continuous parallel digital output of neuronal spike events to a computer. Another computer controlled behavioral events of the experiment (Med Associates, Inc.) and sent digital outputs corresponding to each event (i.e., solenoid opening) to the MAP box to be time stamped along with the neural data. In the present study, typically one or two neurons were recorded per microwire, similar to previous reports (Chang et al. 1994; Nicolelis et al. 1997; Carelli et al. 2000). Perievent histograms were constructed using commercially available software (NeuroExplorer, Nex Technologies). Firing rates per second were calculated for each cell from -10 to +10 sec, relative to start of the intraoral infusion, in 100-msec bins. Data were then imported into MatLab.

For EMG recordings, rats were attached to a second flexible cable and EMG potentials were recorded differentially. Briefly, wires were led to an amplifier (Grass Instruments) and signals were amplified $(100 \times)$ and filtered $(0.3 \mathrm{~Hz}$ low pass; $3 \mathrm{~Hz}$ high pass). Processed, analog signals were then led through a National Instruments board to the same computer that collected electrophysiological data. The same program (Sort Client, Plexon Inc.) that collected electrophysiological data also collected EMG data. To analyze EMG signals, a horizontal threshold was positioned higher than at least $3 \sigma$ of the noise. Threshold crossings were time stamped and examined relative to infusion onset in NeuroExplorer. Statistical analyses of both electrophysiological and EMG signals were performed using commercially available software (Statistica).

\section{Determination of phasic neural responses and statistical analyses}

The firing rate of every neuron was analyzed to determine whether there was a phasic response to the intraoral infusion. On each trial, data were averaged into epochs: baseline ( -10 to 0 sec relative to infusion onset) and each second of the 4-sec intraoral infusion. A one-way ANOVA was then performed on each cell to determine if there was a main effect of epoch $(P<0.05)$. If a cell had a significant main effect of epoch, it was classified as either inhibitory or excitatory based on the direction of change from baseline.

For Paired and Unpaired rats, $\chi^{2}$ analyses were run on the ratio of response types (increases vs. decreases in firing rate) to compare Day 1 and Day 5 conditions. In these analyses, the proportion of response types observed on Day 1 was used to generate expected results on Day 5. Additionally cells that exhibited inhibitory responses were averaged together and cells that exhibited excitatory responses were averaged together. One-way ANOVAs were then conducted on these two types of responses to determine if there was a significant main effect of epoch. This was performed for the recordings made on Day 1 of sucrose exposure and again on Day 5. Finally, the firing rate of each phasic cell was normalized (Tindell et al. 2006). All phasic cells, regardless of direction of change, were averaged together for Day 1 
and for each group on Day 5 to reveal the overall population response of phasic cells.

\section{Histology}

Following experiments, rats were deeply anesthetized with ketamine/xylazine, and electrode tips were marked by passing current $(13.5 \mu \mathrm{A}, 5 \mathrm{sec})$ through the electrodes. Rats were then transcardially perfused with saline and a $3 \%$ potassium ferricyanide solution in $10 \%$ formalin. Brains were removed and, after post-fixing and freezing, $50-\mu \mathrm{m}$ coronal sections were made through the forebrain. Sections were then mounted on slides and counterstained with thionin to visualize electrode tips. We implanted a total of 192 electrodes in 12 rats. Of those 192, 165 electrodes were located in the nucleus accumbens, with 95 electrodes in the shell and 70 electrodes in the core subregions. There appeared to be no difference in response types across core and shell subregions, although subsequent experiments will explore this further. Only data from electrode placements within the borders of the NAc, as depicted in the atlas of Paxinos and Watson (2007), are presented here.

\section{Acknowledgments}

This work was supported by NIH Grants DA025634 (M.F.R.), DA025679 (R.A.W.), DA027127 (J.D.R.), and DA014339 (R.M.C.).

\section{References}

Barot SK, Kyono Y, Clark EW, Bernstein IL. 2008. Visualizing stimulus convergence in amygdala neurons during associative learning. Proc Natl Acad Sci 105: 20959-20963.

Becerra L, Breiter HC, Wise R, Gonzalez RG, Borsook D. 2001. Reward circuitry activation by noxious thermal stimuli. Neuron 32: 927-946.

Bernstein IL, Chavez M, Allen D, Taylor EM. 1992. Area postrema mediation of physiological and behavioral effects of lithium chloride in the rat. Brain Res 575: 132-137.

Berridge KC. 2009. "Liking" and "wanting" food rewards: Brain substrates and roles in eating disorders. Physiol Behav 97: 537-550.

Blaiss CA, Janak PH. 2009. The nucleus accumbens core and shell are critical for the expression, but not the consolidation, of Pavlovian conditioned approach. Behav Brain Res 200: 22-32.

Boudreau AC, Reimers JM, Milovanovic M, Wolf ME. 2007. Cell surface AMPA receptors in the rat nucleus accumbens increase during cocaine withdrawal but internalize after cocaine challenge in association with altered activation of mitogen-activated protein kinases. J Neurosci 27: 10621-10635.

Cardinal RN, Parkinson JA, Lachenal G, Halkerston KM, Rudarakanchana N, Hall J, Morrison CH, Howes SR, Robbins TW, Everitt BJ. 2002. Effects of selective excitotoxic lesions of the nucleus accumbens core, anterior cingulate cortex, and central nucleus of the amygdala on autoshaping performance in rats. Behav Neurosci 116: $553-567$.

Carelli RM, Deadwyler SA. 1994. A comparison of nucleus accumbens neuronal firing patterns during cocaine self-administration and water reinforcement in rats. $J$ Neurosci 14: $7735-7746$.

Carelli RM, Ijames SG, Crumling AJ. 2000. Evidence that separate neural circuits in the nucleus accumbens encode cocaine versus "natural" (water and food) reward. J Neurosci 20: 4255-4266.

Carlezon WA Jr, Thomas MJ. 2009. Biological substrates of reward and aversion: A nucleus accumbens activity hypothesis. Neuropharmacology 56 (Suppl 1): 122-132.

Chang JY, Sawyer SF, Lee RS, Woodward DJ. 1994. Electrophysiological and pharmacological evidence for the role of the nucleus accumbens in cocaine self-administration in freely moving rats. J Neurosci 14: $1224-1244$

Cooper JC, Knutson B. 2008. Valence and salience contribute to nucleus accumbens activation. NeuroImage 39: 538-547.

Cota D, Tschop MH, Horvath TL, Levine AS. 2006. Cannabinoids, opioids and eating behavior: The molecular face of hedonism? Brain Res Rev 51: 85-107.

Day JJ, Wheeler RA, Roitman MF, Carelli RM. 2006. Nucleus accumbens neurons encode Pavlovian approach behaviors: Evidence from an autoshaping paradigm. Eur J Neurosci 23: 1341-1351.

Ferreira G, Ferry B, Meurisse M, Levy F. 2006. Forebrain structures specifically activated by conditioned taste aversion. Behav Neurosci 120: 952-962.
Garcia J, Hankins WG, Rusiniak KW. 1974. Behavioral regulation of the milieu interne in man and rat. Science 185: 824-831.

German PW, Fields HL. 2007. Rat nucleus accumbens neurons persistently encode locations associated with morphine reward. J Neurophysiol 97: 2094-2106.

Gottfried JA, O'Doherty J, Dolan RJ. 2002. Appetitive and aversive olfactory learning in humans studied using event-related functional magnetic resonance imaging. J Neurosci 22: 10829-10837.

Grill HJ, Norgren R. 1978. The taste reactivity test. I. Mimetic responses to gustatory stimuli in neurologically normal rats. Brain Res 143: $263-279$.

Grill HJ, Roitman MF, Kaplan JM. 1996. A new taste reactivity analysis of the integration of taste and physiological state information. Am J Physiol 271: R677-687.

Hoebel BG, Avena NM, Rada P. 2007. Accumbens dopamineacetylcholine balance in approach and avoidance. Curr Opin Pharmacol 7: $617-627$.

Kaplan JM, Roitman MF, Grill HJ. 1995. Ingestive taste reactivity as licking behavior. Neurosci Biobehav Rev 19: 89-98.

Kourrich S, Rothwell PE, Klug JR, Thomas MJ. 2007. Cocaine experience controls bidirectional synaptic plasticity in the nucleus accumbens. J Neurosci 27: 7921-7928.

Krause M, German PW, Taha SA, Fields HL. 2010. A pause in nucleus accumbens neuron firing is required to initiate and maintain feeding. J Neurosci 30: 4746-4756.

Levita L, Hare TA, Voss HU, Glover G, Ballon DJ, Casey BJ. 2009. The bivalent side of the nucleus accumbens. NeuroImage 44: 1178-1187.

Mahler SV, Smith KS, Berridge KC. 2007. Endocannabinoid hedonic hotspot for sensory pleasure: Anandamide in nucleus accumbens shell enhances "liking" of a sweet reward. Neuropsychopharmacology 32: 2267-2278.

Maldonado-Irizarry CS, Kelley AE. 1995. Excitotoxic lesions of the core and shell subregions of the nucleus accumbens differentially disrupt body weight regulation and motor activity in rat. Brain Res Bull 38: 551-559.

McGinty VB, Grace AA. 2009. Timing-dependent regulation of evoked spiking in nucleus accumbens neurons by integration of limbic and prefrontal cortical inputs. J Neurophysiol 101: 1823-1835.

Meredith GE. 1999. The synaptic framework for chemical signaling in nucleus accumbens. Ann N Y Acad Sci 877: 140-156.

Nicola SM, Yun IA, Wakabayashi KT, Fields HL. 2004a. Cue-evoked firing of nucleus accumbens neurons encodes motivational significance during a discriminative stimulus task. J Neurophysiol 91: 1840-1865.

Nicola SM, Yun IA, Wakabayashi KT, Fields HL. 2004b. Firing of nucleus accumbens neurons during the consummatory phase of a discriminative stimulus task depends on previous reward predictive cues. J Neurophysiol 91: 1866-1882.

Nicolelis MA, Ghazanfar AA, Faggin BM, Votaw S, Oliveira LM. 1997. Reconstructing the engram: Simultaneous, multisite, many single neuron recordings. Neuron 18: 529-537.

Paxinos G, Watson C. 2007. The rat brain in stereotaxic coordinates. Academic Press, London, UK.

Pecina S, Berridge KC. 2005. Hedonic hot spot in nucleus accumbens shell: Where do mu-opioids cause increased hedonic impact of sweetness? J Neurosci 25: 11777-11786.

Reynolds SM, Berridge KC. 2002. Positive and negative motivation in nucleus accumbens shell: Bivalent rostrocaudal gradients for GABA-elicited eating, taste "liking" / disliking" reactions, place preference/avoidance, and fear. J Neurosci 22: 7308-7320.

Roitman MF, Wheeler RA, Carelli RM. 2005. Nucleus accumbens neurons are innately tuned for rewarding and aversive taste stimuli, encode their predictors, and are linked to motor output. Neuron 45: 587-597.

Saper CB, Chou TC, Elmquist JK. 2002. The need to feed: Homeostatic and hedonic control of eating. Neuron 36: 199-211.

Schafe GE, Seeley RJ, Bernstein IL. 1995. Forebrain contribution to the induction of a cellular correlate of conditioned taste aversion in the nucleus of the solitary tract. J Neurosci 15: 6789-6796.

Setlow B, Schoenbaum G, Gallagher M. 2003. Neural encoding in ventral striatum during olfactory discrimination learning. Neuron 38: 625-636.

Stratford TR, Kelley AE. 1997. GABA in the nucleus accumbens shell participates in the central regulation of feeding behavior. J Neurosci 17: $4434-4440$.

Taha SA, Fields HL. 2005. Encoding of palatability and appetitive behaviors by distinct neuronal populations in the nucleus accumbens. J Neurosci 25: $1193-1202$.

Taha SA, Fields HL. 2006. Inhibitions of nucleus accumbens neurons encode a gating signal for reward-directed behavior. J Neurosci 26: 217-222. 
Tindell AJ, Smith KS, Pecina S, Berridge KC, Aldridge JW. 2006. Ventral pallidum firing codes hedonic reward: When a bad taste turns good. J Neurophysiol 96: 2399-2409.

Travers JB, Norgren R. 1986. Electromyographic analysis of the ingestion and rejection of sapid stimuli in the rat. Behav Neurosci 100: $544-555$.

Uchida T, Adachi K, Fujita S, Lee J, Gionhaku N, Cools AR, Koshikawa N. 2005. Role of GABA(A) receptors in the retrorubral field and ventral pallidum in rat jaw movements elicited by dopaminergic stimulation of the nucleus accumbens shell. Eur J Pharmacol 510: 39-47.

Wheeler RA, Twining RC, Jones JL, Slater JM, Grigson PS, Carelli RM. 2008 Behavioral and electrophysiological indices of negative affect predict cocaine self-administration. Neuron 57: 774-785.

Received April 13, 2010; accepted in revised form August 12, 2010. 


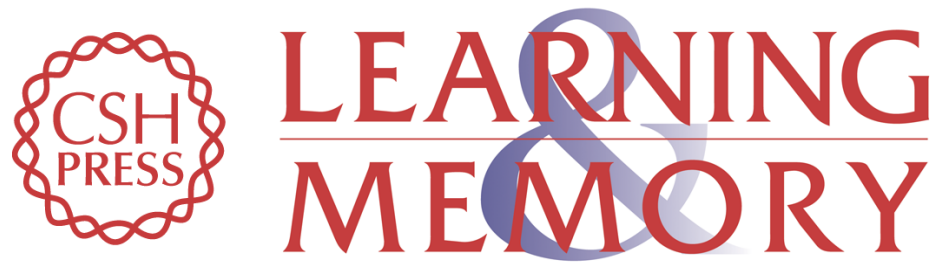

\section{Hedonic and nucleus accumbens neural responses to a natural reward are regulated by aversive conditioning}

Mitchell F. Roitman, Robert A. Wheeler, Paul H.E. Tiesinga, et al.

Learn. Mem. 2010, 17:

Access the most recent version at doi:10.1101//m.1869710

Supplemental
Material http://learnmem.cshlp.org/content/suppl/2010/10/22/17.11.539.DC1

References This article cites 45 articles, 15 of which can be accessed free at:

http://learnmem.cshlp.org/content/17/11/539.full.html\#ref-list-1

License

Email Alerting Receive free email alerts when new articles cite this article - sign up in the box at the Service top right corner of the article or click here. 